\title{
Extraction of oligosaccharides and phenolic compounds by roasting pretreatment and enzymatic hydrolysis from spent coffee ground
}

\author{
Rizwan A. Bhaturiwala*, Hasmukh A. Modi \\ Department of Life Science, School of Science, Gujarat University, Ahmedabad, India.
}

\begin{tabular}{l}
\hline ARTICLE INFO \\
\hline Article history: \\
Received on: February 28, 2020 \\
Accepted on: May 23, 2020 \\
Available online: July 30, 2020 \\
\hline
\end{tabular}

\section{Key words:}

Spent coffee ground, enzymatic hydrolysis, $\beta$-mannanase, roasting pretreatment, oligosaccharides.

\begin{abstract}
Spent coffee ground (SCG) is the waste generated during the preparation of instant coffee and is the source of industrially valuable organic compounds. In this article, SCG was pretreated by roasting at $150^{\circ} \mathrm{C}$ for 30 minutes and heated with water at $90^{\circ} \mathrm{C}$ for extracting carbohydrates and phenolic compounds, after which $1.0 \%(\mathrm{w} / \mathrm{w}) \beta$-mannanase was applied for the hydrolysis of pretreated SCG. SCG is characterized in terms of its total sugar content by the anthrone-sulfuric assay and phenolic compounds by Folin-Ciocalteu's procedure. In this study, the total sugar increased by $14.79 \%(\mathrm{w} / \mathrm{w})$ by the roasting process, and subsequently enzymatic hydrolysis increased the total sugar yield up to $17.43 \%$ (w/w) compared to the untreated SCG, i.e., $10.24 \%$ $(\mathrm{w} / \mathrm{w})$. The reducing sugar was estimated by the dinitrosalicylic acid method and the end product increased to 106.10 (mg Glucose/g) from the initial content 5.32 (mg Glucose/g raw SCG). The total phenolic compound increased to 291.86 (mg Gallic acid/g lyophilized material), which was a 6.39-fold increase compared to the native SCG (45.68 mg Gallic acid/g). These results point to the valuable compounds present in SCG, can be enhanced by combining the roasting pretreatment and enzymatic hydrolysis, and can be utilized in the food and biotech industries.
\end{abstract}

\section{INTRODUCTION}

Instant coffee from the coffee machine is one of the most popular and preferred beverages around the world, which produces around 6 million tons of spent coffee ground (SCG) per year [1]. The increase in the consumption of coffee beverages has in turn increased coffee bean production by $17.0 \%$ from 2002 to 2014, and generated SCG waste is a major concern for the environment [2]. Spent coffee waste contains various organic compounds, such as carbohydrates, lignin, fatty acids, and antioxidant compounds, which make it an excellent candidate for the production of valueadded substances [3].

Occasionally, SCG is used as fuel in industrial boilers [4]. However, due to the high lignin content in SCG, it cannot be used for animal feed [5]. SCG can also be used for biodiesel production [6]. The determination of amino acids [7], sugars [1], and oil contents [8,9] in SCG has also been carried out, aiming to find alternatives for the reuse of this residue. The use of SCG has been developed in

*Corresponding Author

Rizwan A. Bhaturiwala, Department of Life Science, School of Science, Gujarat University, Ahmedabad, India.E-mail: bhaturiwala@gmail.com fermentation technology [10]. Acid hydrolysis pretreated SCG was used for ethanol production by Saccharomyces cerevisiae [11]. Different approaches have been made for the extraction of polysaccharides from SCG, mainly using the chemical agent for extraction. The acid and alkali agents have been used, such as diluted sulfuric acid [1], potassium hydroxide [12], and sodium hydroxide $[13,14]$. Several other polysaccharides extraction methods were reported, such as steam explosion [15], using the subcritical water [16] and enzymatic hydrolysis [3].

The composition of SCG is rich in polymeric sugars, in particular hemicellulose and cellulose structures, which comprise almost half of the material dry weight, whereas the mannan content, such as galactomannan, is almost $20 \%-30 \%$ of the dry weight [17]. These polysaccharides are arranged in the mannose chain or mannose with glucose (GLU) linked by one to four linkages [18]. In general, these polysaccharides are higher in molecular weight, and a large portion will remain unhydrolyzed during the enzymatic hydrolysis. Nonetheless, the roasting process enhances the debranching of galactomannans, thus increasing their extraction and solubility and does not require any chemical agent during the process [19]. The enzyme involved in breaking 
the mannan structure and resulting in manno-oligosaccharides (MOS) production is $\beta$-mannanase (EC 3.2.1.78), which has an endo-action on the polysaccharides [20].

The main goal of this study is to extract the polysaccharides and phenolic compounds from SCG by the roasting process and to evaluate the alteration in extracted compounds, and subsequently hydrolyze the major polysaccharides structure present in SCG, i.e., galactomannan, using the partially purified $\beta$-mannanase from Streptomyces sp. RDA1496.

\section{MATERIALS AND METHODS}

\subsection{Raw Material}

SCGs were collected from Café Coffee Day (Coffee shop, Panjrapol, Ahmedabad, Gujarat). The collected SCG samples were oven-dried at $55^{\circ} \mathrm{C}$ for 2 hours to remove the excess water and were stored using an airtight container at $4{ }^{\circ} \mathrm{C}$ for further use.

\subsection{Enzyme Production and Purification}

$\beta$-mannanase was produced from a strain isolated from the soil and defined as Streptomyces sp. RDA1496 (GenBank: KX656177.1), using the following medium components and conditions: guar gum $7.09 \mathrm{~g} / 1$, peptone $4.90 \mathrm{~g} / 1$, fructose $4.81 \mathrm{~g} / 1, \mathrm{NaCl} 2.0 \mathrm{~g} / 1$, $\mathrm{K}_{2} \mathrm{HPO}_{4} 2.05 \mathrm{~g} / 1, \mathrm{CaCl}_{2} 0.5 \mathrm{~g} / 1$, inoculum size $3.0 \%$, medium volume $100.0 \mathrm{ml}$, initial $\mathrm{pH} 8.0$, temperature $30^{\circ} \mathrm{C}$ with static condition, and incubated for 72 hours. Extraction of $\beta$-mannanase was carried out by centrifugation at $1480 \mathrm{~g}$ for 15 minutes at $4^{\circ} \mathrm{C}$. The supernatant was used as the source of enzyme and was subjected to precipitation using $40.0 \%$ of ammonium sulfate in the saturation level, $4{ }^{\circ} \mathrm{C}$ temperature, and 6 hours of incubation. The collected precipitate was centrifuged at $9250 \mathrm{~g}$ for 10 minutes under the $4^{\circ} \mathrm{C}$; after centrifugation, the supernatant was discarded and the obtained pellets were redissolved in a 20 $\mathrm{mM}$ phosphate buffer ( $\mathrm{pH}$ 8.0). Subsequently, the enzyme was dialyzed against the same buffer using the dialysis membrane (Himedia LA395-110). The dialyzed $\beta$-mannanase was used for the hydrolysis of SCG. The described production medium, conditions, and purification process were optimized during an earlier research study.

\subsection{Enzyme Activity Assay}

$\beta$-mannanase activity was assayed in the reaction mixture consisting of $0.5 \mathrm{ml}$ of $50 \mathrm{mM}$ potassium phosphate buffer $(\mathrm{pH}$ 7.0) containing $1.0 \%$ locust bean gum (Hi-media MumbaiINDIA) with $0.5 \mathrm{ml}$ of the supernatant enzyme at $45^{\circ} \mathrm{C}$ for 30 minutes, which is a modified method of El-Naggar et al. [21]. The dinitrosalicylic acid reagent was used to determine the amount of released reducing sugar [22]. One unit of $\beta$-mannanase activity was defined as the amount of enzyme producing 1 micromole of reducing sugar per minute under the experimental assay conditions. The amount of reducing sugar was compared to using the prepared standard graph of mannose.

\section{Spent Coffee Ground (SCG)}

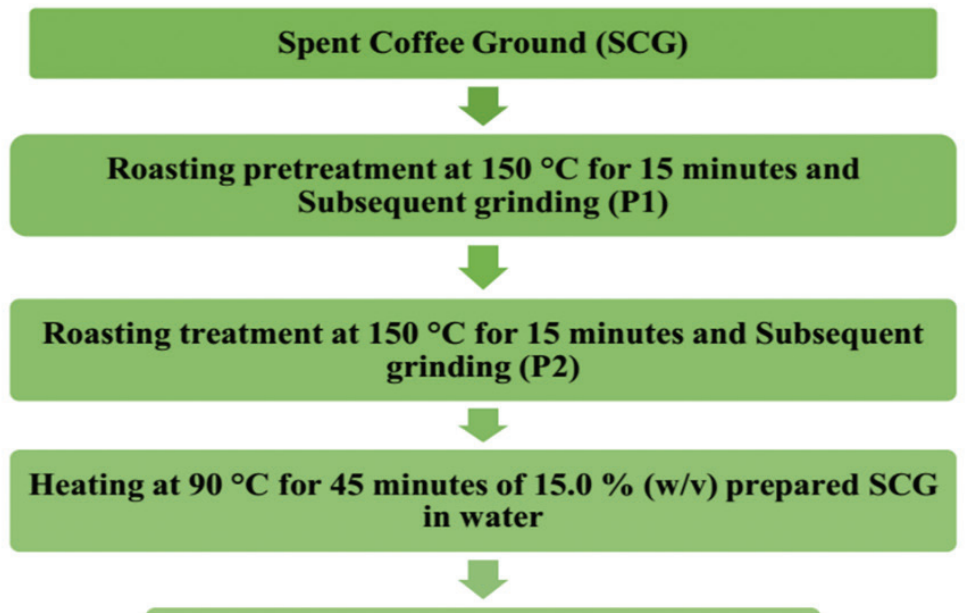

Centrifuge at $2500 \mathrm{rpm}$ for 10 minutes

\section{Hydrolysis using $\beta$-Mannanase (S1E)}

Hydrolysis using $\beta$-Mannanase (R1E)

Figure 1: Flow diagram of the spent coffee ground treatment process and enzymatic hydrolysis. 


\subsection{Roasting as Pretreatment}

Roasting process increases the extractability of polysaccharides without altering or damaging the internal hemicellulosic structure and can be an important pretreatment for the production of oligosaccharides using enzymatic hydrolysis. In this study, $200 \mathrm{~g}$ of SCG sample was kept at $150^{\circ} \mathrm{C}$ for 15 minutes (Muffle furnace, Purvi Enterprise, Gujarat). The sample was crushed using a hand blender and was labeled as (P1). From the sample (P1), $100 \mathrm{~g}$ was stored for analysis and $100 \mathrm{~g}$ was used for a repeated roasting process, which was kept at $150^{\circ} \mathrm{C}$ for 15 minutes and crushed using the hand blender and labeled as (P2). Subsequently, from the sample (P2), $15.0 \mathrm{~g}$ of SCG was dissolved in $100 \mathrm{ml}$ distilled water and heated at $90^{\circ} \mathrm{C}$ for 45 minutes, and subsequently cooled at room temperature. The sample was centrifuged $(910 \mathrm{~g}$ for 10 minutes at room temperature), and the supernatant and residues were collected separately. The residues and supernatant were lyophilized and labeled as S1 (supernatant 1) and R1 (residue 1), respectively. The prepared study design was modified by the research work reported in Joanna et al. [23]. The lyophilized samples were subjected to enzymatic hydrolysis using the dialyzed $\beta$-mannanase $(353.48 \mathrm{IU} / \mathrm{ml})$ produced by Streptomyces $s p$. RDA1496. The flowchart showing roasting pretreatment of $\mathrm{SCG}$ is shown in Figure 1.

\subsection{Enzymatic Hydrolysis}

The pretreated lyophilized samples of SCG, i.e., residue (R1) and supernatant (S1), were subjected to enzymatic hydrolysis. The effect of $\beta$-mannanase enzymes on pretreated SCG was measured by the addition of $1.00 \%(\mathrm{w} / \mathrm{w})$ dialyzed $\beta$-mannanase (358 IU/ $\mathrm{ml})$ to the lyophilized sample of the supernatant (S1) and the residue (R1). Enzymatic hydrolysis was carried out at $45^{\circ} \mathrm{C}$ for 20 hours with an agitation rate of $60 \mathrm{rpm}$. After the completion of hydrolysis, the solutions were heated for 10 minutes at $90^{\circ} \mathrm{C}$ for enzyme deactivation [24]. After enzymatic hydrolysis the samples labeled as S1E (enzymatically hydrolyzed supernatant 1) and R1E (enzymatically hydrolyzed residue 1) were lyophilized, and the dried samples were used for further analysis.

\subsection{Analysis of SCG Samples}

For the determination of mono and polysaccharide contents and phenolic compounds in treated SCG, the treated lyophilized material (LM) was dissolved in distilled water to obtain a concentration of $1.5 \mathrm{mg} / \mathrm{ml}$ [25]. The samples were vortexed for 1 minute, filtered through Whatman's filter paper no four, and then stored for further analysis.

\subsubsection{Estimation of total sugars}

The anthrone-sulfuric acid assay was used to determine the total sugar present in the roasted and enzymatic hydrolyzed SCG samples. A $50 \mu 1$ aliquot of samples was taken from P1, P2, S1, $\mathrm{R} 1, \mathrm{~S} 1 \mathrm{E}$, and R1E, and $150 \mu \mathrm{l}$ anthrone reagent was added into the respective samples. The reaction mixtures were allowed to react at $4^{\circ} \mathrm{C}$ for 10 minutes and further incubated for 20 minutes at $100^{\circ} \mathrm{C}$. The samples were allowed to cool down for 20 minutes and absorbance reading was taken at $620 \mathrm{~nm}$ (microplate reader). The results were compared to the prepared standard graph and the total sugars were expressed in $\mathrm{g}$ GLU/100 $\mathrm{g}$ of LM [25].

\subsubsection{Estimation of reducing sugar}

The prepared $1.5 \mathrm{mg} / \mathrm{ml}$ samples were further analyzed to estimate the reducing sugar by the DNSA method [22], and expressed as $\mathrm{mg} \mathrm{GLU} / \mathrm{g}$.

\subsubsection{Estimation of total phenolic content}

Total phenolic content was measured using Folin-Ciocalteu's reagent and the value was calculated using the standard gallic acid (GAE) graph. For different samples, 1:20 dilution ratio was prepared. A $100 \mu \mathrm{l}$ of the diluted sample was mixed with $500 \mu \mathrm{l}$ of Folin-Ciocalteu's reagent and $7.90 \mathrm{ml}$ demineralized water. Then, $1.5 \mathrm{ml}$ of $7.5 \%(\mathrm{w} / \mathrm{v})$ sodium carbonate was mixed after 2 minutes with these samples. Subsequently, the samples were kept in the dark for 90 minutes. The absorbance was measured at $765 \mathrm{~nm}$. The results were expressed in $\mathrm{mg}$ GAE/g [26].

\subsection{Thin-Layer Chromatography (TLC) of Hydrolysis Products}

TLC was carried out for the detection of hydrolyzed products using TLC silica gel 60 sheets (Merck, Darmstadt, Germany), modified by the method in Wongsiridetchai et al.'s study [27]. All samples were applied in equal quantities of $5 \mu 1$ and run with the mobile phase solvent mixture of isopropyl alcohol/ethyl acetate/water in the ratio of $2: 2: 1$. The brown spot of the product was developed by spraying $0.2 \%(\mathrm{w} / \mathrm{v})$ orcinol dissolved in $10.0 \%(\mathrm{v} / \mathrm{v}) \mathrm{H}_{2} \mathrm{SO}_{4}$ and placed in the oven at $80^{\circ} \mathrm{C}$ for 5 minutes for the visualization of spots.

\subsection{Fourier-transform infrared spectroscopy (FTIR) Analysis}

FTIR analysis of the molecular structure and functional group of elements present in the crude and hydrolyzed SCG sample (S1E) were carried out using the Alpha FTIR spectrophotometer from Bruker. The transmission was measured with 20 scans per sample from 4000 to $500 \mathrm{~cm}^{-1}$ and a resolution of $4 \mathrm{~cm}^{-1}$.

\section{RESULTS AND DISCUSSION}

\subsection{Roasting Pretreatment for SCG}

The fraction of carbohydrates in SCG is not easily accessible by the enzymatic hydrolysis and, therefore, requires certain physical and chemical pretreatments to extract the polysaccharide content from the SCG. In this study, we selected roasting as a pretreatment process for SCG and the analytical results of the pretreated SCG sample are presented in Table 1.

The obtained value of the total sugar for crude SCG was found to be $10.26 \pm 0.11 \mathrm{~g} \mathrm{GLU} / 100 \mathrm{~g} \mathrm{SCG}$ and was very low in the amount of reducing sugar, i.e., $5.32 \pm 0.05$. The first step $(\mathrm{P} 1)$ of roasting pretreatment increased the amount of reducing sugar as well as the total sugar. Similarly, in a subsequent step of roasting (P2), the amount of total sugar increased to $13.39 \pm 0.025 \mathrm{~g} \mathrm{GLU} / 100 \mathrm{~g}$, and reducing sugar was $42.44 \pm 1.34 \mathrm{mg} \mathrm{GLU} / \mathrm{g}$.

The pretreated sample (P2) was heated at $90^{\circ} \mathrm{C}$ for 45 minutes and the supernatant (S1) and residue (R1) were lyophilized. The lyophilized samples S1 and R1 were found to have total sugar of $9.52 \pm 0.108 \mathrm{~g} \mathrm{GLU} / 100 \mathrm{~g}$ and $5.27 \pm 0.034 \mathrm{~g} \mathrm{GLU} / 100 \mathrm{~g}$, respectively. The amount of reducing sugar was increased in S1 
Table 1: The amount of polysaccharides and phenolic compounds extracted by the pretreatment process.

\begin{tabular}{|c|c|c|c|}
\hline Sample & Total sugar $^{\mathrm{a}}$ & Reducing sugar $^{\mathbf{b}}$ & Phenolic compound $^{\mathrm{c}}$ \\
\hline SCG & $10.26 \pm 0.11$ & $5.32 \pm 0.05$ & $45.68 \pm 2.33$ \\
\hline P1 & $11.58 \pm 0.03$ & $22.05 \pm 0.65$ & $98.76 \pm 2.34$ \\
\hline P2 & $13.39 \pm 0.025$ & $42.44 \pm 1.34$ & $113.89 \pm 3.09$ \\
\hline S1 (LM) & $9.52 \pm 0.108$ & $64.50 \pm 2.54$ & $156.54 \pm 2.34$ \\
\hline R1 (LM) & $5.27 \pm 0.034$ & $12.98 \pm 2.34$ & $110.45 \pm 3.53$ \\
\hline
\end{tabular}

$(64.50 \pm 2.54 \mathrm{mg}$ GLU/g) compared to R1 $(12.98 \pm 2.34 \mathrm{mg}$ $\mathrm{GLU} / \mathrm{g}$ ) of the samples. It can be observed that by the roasting pretreatment process, the total sugar $(14.79 \pm 0.142 \mathrm{~g} \mathrm{GLU} / 100$ g) and reducing sugar $(77.48 \pm 4.88 \mathrm{mg} \mathrm{GLU} / \mathrm{g})$ contents of SCG were increased, which can be used as a fermentation substrate. The phenolic compounds were also increased to $266.99 \pm 5.87$ due to the roasting pretreatment.

In an earlier report, SCG was treated by the roasting process at different temperatures, i.e., at $160^{\circ} \mathrm{C}$ and $220^{\circ} \mathrm{C}$ for 2 and 1 hours, respectively. Subsequently, the samples were dissolved in hot water at $90^{\circ} \mathrm{C}$ for 1 hour and treated with alkali solution using the $4 \mathrm{M} \mathrm{NaOH}$ for 2 hours. Roasting pretreatment increased the extracted mannan polysaccharide content by $15.0 \%$ of the total polysaccharides at $160^{\circ} \mathrm{C}$; similarly, in our research work, the total sugar content was increased by $14.79 \%(\mathrm{w} / \mathrm{w})$ from $10.26 \%$ (w/w) of raw SCG by the roasting process. The subsequent alkali treatment $(4 \mathrm{M} \mathrm{NaOH})$ increased the MOS content by $56.0 \%$ at $60^{\circ} \mathrm{C}$ and $120^{\circ} \mathrm{C}$ compared to the available sugar in raw SCG [23]. In another report, the researcher carried out steam explosion as a pretreatment at various temperatures from $150^{\circ} \mathrm{C}$ to $210^{\circ} \mathrm{C}$ for 15 minutes and processed enzymatic hydrolysis. Steam pretreatment recovered the highest soluble solid of $10.7 \%$ at $210^{\circ} \mathrm{C}$ for 15 minutes [28].

The extraction of polysaccharides was also reported using the autohydrolysis process $\left(160^{\circ} \mathrm{C}-200^{\circ} \mathrm{C}\right)$, and the optimum conditions were determined using the central composite design. The best yield of polysaccharides was observed at $160^{\circ} \mathrm{C}$ for 10 minutes, using liquid/solid ratio of $15 \mathrm{ml}$ water/g SCG. The highest amount of polysaccharides was extracted by $33.25 \%$ of SCG using the central composite design; additionally, the treated lyophilized sample contained $234.1407 \mathrm{mg} \mathrm{GAE} / \mathrm{g}$ of phenolic compounds [25]. In a similar report, Passos et al. [29] studied the microwaveassisted extraction of MOS from SCG using different temperature conditions $\left(200^{\circ} \mathrm{C}, 170^{\circ} \mathrm{C}\right.$, and $\left.140^{\circ} \mathrm{C}\right)$ and time $(2,5$, and 10 minutes). The extraction of galactomannans is favored at $170^{\circ} \mathrm{C}$ within the selected incubation time; the galactomannans' chain length was shown to decrease proportionally to the temperature increase. Galactose had a high increase from $1.5 \%$ to $5.7 \%$ when the temperature increased from $140^{\circ} \mathrm{C}$ to $170^{\circ} \mathrm{C}$, contributing to $50 \%$ of the extracted sugar content.

\subsection{Enzymatic Hydrolysis of Crude and Pretreated SCG}

A $1 \%(\mathrm{w} / \mathrm{w}) \quad \beta$-mannanase enzyme $(353.48 \mathrm{IU} / \mathrm{ml})$ was used to hydrolyze the pretreated samples of SCG. The hydrolyzed
Table 2: The amount of polysaccharides and phenolic compounds released by enzymatic hydrolysis.

\begin{tabular}{|c|c|c|c|}
\hline Sample & Total sugar ${ }^{\mathrm{a}}$ & Reducing sugar ${ }^{b}$ & Phenolic compound ${ }^{\mathrm{c}}$ \\
\hline SCG & $10.26 \pm 0.11$ & $5.32 \pm 0.05$ & $45.68 \pm 2.33$ \\
\hline SCG (E) & $11.48+0.54$ & $13.98+0.21$ & $78.57+3.57$ \\
\hline S1 (E) (LM) & $11.42+0.03$ & $89.55+3.89$ & $188.75+4.52$ \\
\hline R1 (E) (LM) & $6.01+0.02$ & $16.55+1.86$ & $103.11+4.56$ \\
\hline
\end{tabular}

SCG showed an increase in the amount of total reducing sugar $\mathrm{S} 1(\mathrm{E})+\mathrm{R} 1(\mathrm{E})$, i.e., $106.10 \pm 5.75(\mathrm{mg} \mathrm{GLU} / \mathrm{g} \mathrm{LM})$. The amount of total sugar was increased 1.69-fold compared to raw SCG (Table 2). The phenolic content was also affected by the pretreatment and enzymatic hydrolysis of the SCG. The total phenolic compound of (S1E+R1E) was increased to 291.86 (mg Gallic acid/g LM).

The enzymatic hydrolysis of SCG without pretreatment was evaluated and the amount of reducing sugar was lower compared to the pretreated sample. The increase in the reducing sugar was observed to be $106.10 \pm 5.75 \mathrm{mg}$ GLU/g LM in the roasting pretreated with enzymatically hydrolyzed $(\mathrm{S} 1 \mathrm{E}+\mathrm{R} 1 \mathrm{E})$ samples and to be $13.98 \pm 0.21 \mathrm{mg} \mathrm{GLU} / \mathrm{g}$ LM in SCG (E) enzymatically treated without roasting pretreatment from the initially untreated sample, i.e., $5.32 \pm 0.05 \mathrm{mg} \mathrm{GLU} / \mathrm{g}$. This can be explained by the impact of roasting process on the cellulosic and hemicellulosic structures of SCG. The roasting process promotes the untying of the complex internal structure of SCG, and thus reducing the size of high molecular weight polysaccharides. The roasting pretreated SCG was more amenable for enzymatic hydrolysis compared to raw SCG, resulting in a higher amount of reducing sugar in S1E and R1E.

Chiyanzu et al. [28] used the cocktail of mannanase (from Yarrowia lipolytica) and cellulase (Acremonium, Bioshigen Co.Ltd, Japan) enzymes at the $0.01 / 0.91 \%(\mathrm{w} / \mathrm{w})$ concentration for the hydrolysis of steam-treated SCG, respectively. The applied enzyme cocktail for hydrolysis resulted in the increase in soluble solids containing polysaccharides by $22.6 \%$ (g per $100 \mathrm{~g}$ pretreated SCG), which is higher compared to our results, i.e., $17.43 \%(\mathrm{w} / \mathrm{w})$ of SCG. In another report, the cocktail of enzymes (mannanase, endoglucanase, exoglucanase, xylanase, and pectinase) was used for the hydrolysis of SCG. The enzymatic hydrolysis was carried out at $40^{\circ} \mathrm{C}$ for xylanase and $60^{\circ} \mathrm{C}$ and for other enzymes for 18 hours of incubation. The maximum SCG hydrolyzed yield of polysaccharides was recovered by $17 \%$ from enzymatic hydrolysis [24]. Ravindran et al. applied eight different pretreatments of varying nature (physical, chemical, and physicochemical), followed by enzymatic hydrolysis for SCG. Sequential pretreatment yielded $350.12 \mathrm{mg}$ of reducing sugar/g of substrate, which was 1.7-fold higher than in native spent coffee waste $(203.4 \mathrm{mg} / \mathrm{g}$ of substrate) [30].

\subsection{Thin-Layer Chromatography}

TLC was carried out for the confirmation of hydrolyzed products. The hydrolyzed products are mainly oligosaccharides and are shown in Figure 2. The TLC for crude SCG shows the presence 

and enzymatic hydrolysis from spent coffee ground 2020;8(04):75-81

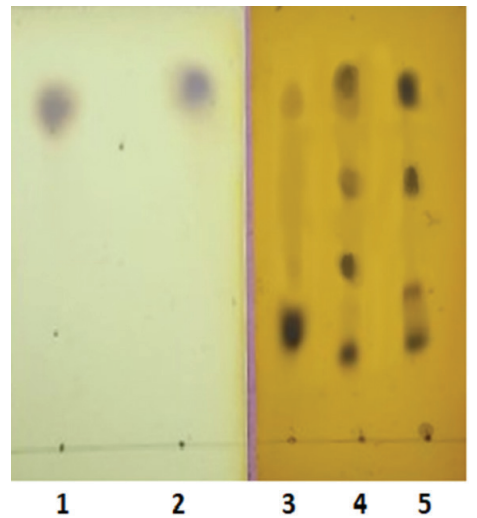

Figure 2: TLC of the hydrolyzed products generated by pretreatment and enzymatic hydrolysis. Lane 1: Glucose (standard); Lane 2: Mannose (standard); Lane 3: Crude SCG; Lane 4: $\beta$-Mannanase hydrolyzed residue (R1E); Lane 5: $\beta$-Mannanase hydrolyzed supernatant (S1E). of polysaccharides in the sample (lane 3). The monomeric, biose, and triose oligosaccharides were detected in lanes 4 and 5 , respectively; similar patterns on TLC of oligosaccharide were observed for alkali pretreated and enzymatically hydrolysed SCG samples using the crude enzyme from Bacillus sp. GA2(1). The TLC results also confirm that the amount of reducing sugar was higher, and mannobiose and mannotriose were oligosaccharide products [27].

\subsection{FTIR Analysis}

The FTIR spectra of crude SCG and treated SCG of S1E were obtained and are shown in Figure 3a and b. The absorbance was measured with 20 scans per sample from 4000 to $500 \mathrm{~cm}^{-1}$ with a resolution of $4 \mathrm{~cm}^{-1}$. The obtained spectrum was found to be a typical carbohydrate pattern of SCG, when matched with other IR spectra of SCG reported in the literature $[25,28]$.
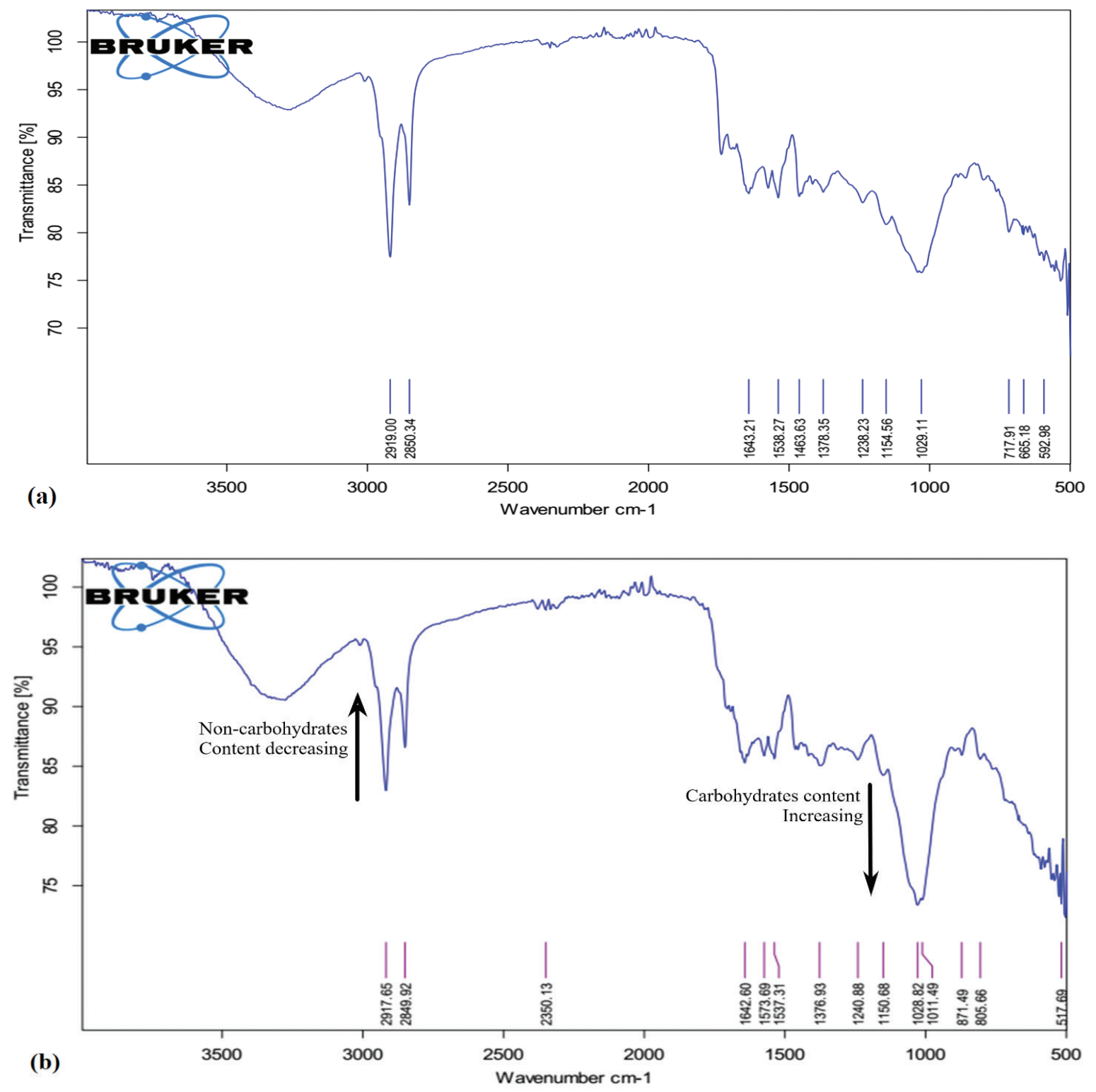

Figure 3: FTIR spectrum analysis of (a) spent coffee ground and (b) pretreated and enzymatically hydrolyzed spent coffee ground (S1E). 
The area between 3,200 and $3,600 \mathrm{~cm}^{-1}$ corresponds to $\mathrm{O}-\mathrm{H}$ stretching vibration of hydroxyl group; the low intensity of band in this area is related to amorphous cellulose [31]. The region of $\mathrm{C}-\mathrm{H}$ vibration between 2,800 and $3000 \mathrm{~cm}^{-1}$ represents hydrocarbon moieties of lignin [32]. The intensity of the observed peaks between 1,500 and $1,700 \mathrm{~cm}^{-1}$ indicates a higher noncarbohydrate fraction mainly due to the lignin component. The IR spectrum between 1,500 and $1,700 \mathrm{~cm}^{-1}$ is associated with the carbonyl group $\mathrm{C}-\mathrm{O}$ stretching vibration [33] and also associated with caffeine and chlorogenic acids [32].

The spectrum between 1,190 and $920 \mathrm{~cm}^{-1}$ is related to stretching vibrations with ring vibration of $(\mathrm{C}-\mathrm{OH})$ side groups and the $(\mathrm{C}-\mathrm{O}-\mathrm{C})$ glycosidic band vibrations is specific for polysaccharides. The low absorbance in this region is related to the low concentration of polysaccharides and it is shown in raw SCG, whereas the spectrum of treated SCG was found to have a high absorbance in this region indicated the high concentration of polysaccharides $[28,31]$. The observed peak in the $808-890 \mathrm{~cm}^{-1}$ range is associated to d-galactopyranose and d-mannopyranose units, respectively [34]. The FTIR analysis of treated S1E indicates the high concentration of MOS compared to crude SCG.

\section{CONCLUSION}

SCG is a source of valuable compounds that cannot beextractable; insoluble solids represent a potential feedstock for MOS and phenolic compounds. During the experiment, roasting pretreatment proved to be significant in the effective extraction of polysaccharides and phenolic compounds from the crude SCG sample. A consecutive strategy of the effects of pretreatments was found to be highly proficient in increasing the reducing sugar yield, when hydrolyzed using $\beta$-mannanase. FTIR analysis revealed breakage of the $\beta$-glyosidic bond between cellulose and hemicellulose in the treated sample compared to raw SCG. The presence of important amounts of MOS in treated SCG can be exploited in the food industries, which could include energy drinks and health supplements. Furthermore, the treated SCG can be used as a medium substrate for biofuel production and other biotechnology production, whereas phenolic-rich extracts can be applied to a variety of food and nutraceutical applications.

\section{ACKNOWLEDGMENT}

The authors acknowledge the funding source as a scholarship from Maulana Azad National Fellowship (MANF) program by the University Grant commission (UGC).

\section{CONFLICT OF INTEREST}

The authors declared that they have no conflict of interest.

\section{REFERENCES}

1. Mussatto SI, Carneiro LM, Silva JPA, Roberto IC, Teixeira JA. A study on chemical constituents and sugars extraction from spent coffee grounds. Carbohyd Polym 2011;83:368-74.

2. Campos-Vega R, Loarca-Piña G, Vergara-Castañeda HA, Oomah BD. Spent coffee grounds: a review on current research and future prospects. Trends Food Sci Technol 2015;45:24-36.
3. Scully DS, Jaiswal AK, Abu-Ghannam N. An investigation into spent coffee waste as a renewable source of bioactive compounds and industrially important sugars. Bioengineering (Basal) 2016;3(4):33.

4. Silva MA, Nebra SA, Machado Silva MJ, Sanchez CG. The use of biomass residues in the Brazilian soluble coffee industry. Biomass Bioenergy 1998;14:457-67.

5. Cruz GM. Resíduos de cultura e indústria. Informe Agropecuário 1983;9:32-7.

6. Sendzikiene E, Makareviciene V, Janulis P, Kitrys S. Kinetics of free fatty acids esterification with methanol in the production of biodiesel fuel. Eur J Lipid Sci Tech 2004;106:831-36.

7. Lago RCA, Antoniassi R, Freitas S. Centesimal composition and amino acids of raw, roasted and spent ground of soluble coffee. In: II Simpósio de Pesquisa dos Cafés do Brasil Vitoria, 2001.

8. Freitas SP, Monteiro PL, Lago RCA. 2000. Extração do óleo da borra de café solúvel com etanol comercial. In: I Simpósio de Pesquisa dos Cafés do Brasil. Poços de Caldas, Brazil, 2000.

9. Kondamudi N, Mohapatra SK, Misra M. Spent coffee grounds as a versatile source of green energy. J Agric Food Chem 2008;56:1175760 .

10. Leifa F, Pandey A, Soccol CR. Production of Flammulina velutipes on coffee husk and coffee spent-ground. Braz Arch Biol Technol 2001;44:205-12.

11. Machado ESM. Reaproveitamento de resíduos da indústria do café como matéria-prima para a produção de etanol. MSc dissertation. Department of Biological Engineering, University of Minho, Braga, Portugal, 2009.

12. Fischer M, Reimann S, Trovato V, Redgwell RJ. Polysaccharides of green Arabica and Robusta coffee beans. Carbohydr Res 2001;330:93101.

13. Ballesteros LF, Cerqueira MA, Teixeira JA, Mussatto SI. Characterization of polysaccharides extracted from spent coffee grounds by alkali pretreatment. Carbohyd Polym 2015;127:347-54.

14. Simões J, Madureira P, Nunes FM, do Rosário DM, Vilanova M, Coimbra MA. Immunostimulatory properties of coffee mannans. Mol Nutr Food Res 2009;53;1036-43.

15. Chiyanzu I, Brienzo M, García-Aparicio MP, Görgens JF. Application of endo- $\beta-1,4, \mathrm{~d}$-mannanase and cellulase for the release of mannooligosaccharides from steam-pretreated spent coffee ground. Appl Biochem Biotechnol 2014;172(7):3538-57.

16. Getachew AC, Chun B. Influence of pretreatment and modifiers on subcritical water liquefaction of spent coffee grounds: a green waste valorization approach. J Clean Prod 2016;142(4):3719-27.

17. Bradbury AGW, Halliday DJ. Chemical structures of green coffee bean polysaccharides. J Agric Food Chem 1990;38:389-92.

18. Petkowicz CLO, Reicher F, Chanzy H, Taravel FR, Vuong R. Linear mannan in the endosperm of Schizolobium amazonicum. Carbohydr Polym 2001;44:107-12.

19. Simões J, Maricato FM, Domingues MR, Coimbra, MA. Thermal stability of spent coffee ground polysaccharides: galactomannans and arabinogalactans. Carbohydr Polym 2014;101:256-64.

20. Arya M, Rao LJM. An impression of coffee carbohydrates. Crit Rev Food Sci Nutr 2007;47:51-67.

21. El-Naggar MY, El-Aassar SA, Youssef AS, El-Sersy NA, Beltagy EA Extracellular $\beta$-mannanase production by the immobilization of the locally isolated Aspergillus niger. Int J Agri Biol 2006;8:57-62.

22. Miller GL. Use of dinitrosalicylic acid reagent for determination of reducing sugar. Anal Chem 1959;31:426-8.

23. Simões J, Nunes FM, Domingues MR, Coimbra M. Extractability and structure of spent coffee ground polysaccharides by roasting pretreatments. Carbohydr Polym 2013;97:81-9.

24. Jooste T, García-Aparicio MP, Brienzo M, VanZyl W, Görgens J. Enzymatic hydrolysis of spent coffee ground. Appl Biochem Biotechnol 2013;169:2248-62. 

and enzymatic hydrolysis from spent coffee ground 2020;8(04):75-81

25. Ballesteros LF, Teixeira JA, Mussatto S. Extraction of polysaccharides by autohydrolysis of spent coffee grounds and evaluation of their antioxidant activity. Carbohyd Polym 2017;157:258-66.

26. Bravo J, Monente C, Juániz, I, De Peña MP, Cid C. Influence of extraction process on antioxidant capacity of spent coffee. Food Res Int 2011;50(2):610-16.

27. Wongsiridetchai C, Chiangkham, W, Khlaihiran N, Sawangwan T, Wongwathanarat $\mathrm{P}$, Charoenrat $\mathrm{T}$, et al. Alkaline pretreatment of spent coffee grounds for oligosaccharides production by mannanase from Bacillus sp. GA2(1). Agric Nat Resour 2018;52;222-7.

28. Chiyanzu I, Brienzo M, García-Aparicio MP, Agudelo RA, Görgens JF. Spent coffee ground mass solubilisation by steam explosion and enzymatic hydrolysis. J Chem Technol Biotechnol 2014;90:449-58.

29. Passos C, Rudnitskaya A, Neves J, Lopes G, Evtuguin D, Coimbra M. Structural features of spent coffee grounds water-soluble polysaccharides: towards tailor-made microwave assisted extractions. Carbohydr Polym 2019;214:53-61.

30. Ravindran R, Jaiswal S, Abu-Ghannam N, Jaiswal A. Two-step sequential pretreatment for the enhanced enzymatic hydrolysis of coffee spent waste. Bioresour Technol 2017;239:276-84.

31. Synytsya A, Novak M. Structural analysis of glucans. Ann Transl Med 2014;2(2):17.
32. Ribeiro JS, Salva TJ, Ferreira MMC. Chemometric studies for quality control of processed brazilian coffees using drifts. J Food Qual 2010;33:212-27.

33. Ren L, Hemar Y, Perera CO, Lewis G, Krissansen GW, Buchanan PK. Antibacterial and antioxidant activities of aqueous extracts of eight edible mushrooms. Bioact Carbohydr Diet Fibre 2014;3:41-51.

34. Figueiró S, Góes JC, Moreira R, Sombra A. On the physico-chemical and dielectric properties of glutaraldehyde crosslinked galactomannancollagen films. Carbohydr Polym 2004;56:313-20.

\section{How to cite this article:}

Bhaturiwala RA, Modi HA. Extraction of oligosaccharides and phenolic compounds by roasting pretreatment and enzymatic hydrolysis from spent coffee ground. J Appl Biol Biotech 2020; 8(04):075-081. DOI: 10.7324/JABB.2020.80412 